\title{
Involvement of bradykinin and bradykinin $B 1$ receptor in patients with endometriosis
}

\author{
XIN MENG $^{1 *}$, YING LI $^{1 *}$, QINGXUE LI $^{2}$, JIAN YANG ${ }^{3}$, MINGLI AN ${ }^{1}$, \\ XINPING FU ${ }^{1}$, SHUANCHENG ZHANG ${ }^{1}$ and JINGWEI CHEN ${ }^{1}$
}

\begin{abstract}
${ }^{1}$ Hebei Key Laboratory of Integrative Medicine on Liver-Kidney Patterns, Institute of Integrative Medicine, Hebei University of Chinese Medicine, Shijiazhuang, Hebei 050091; ${ }^{2}$ Department of Gynecology, The Fourth Hospital of Shijiazhuang, Shijiazhuang, Hebei 050011; ${ }^{3}$ Department of Rehabilitation, Special Care Hospital of Hebei, Shijiazhuang, Hebei 050051, P.R. China
\end{abstract}

Received May 30, 2021; Accepted August 6, 2021

DOI: $10.3892 / \mathrm{etm} .2021 .10675$

\begin{abstract}
Endometriosis (EM), a benign aseptic inflammatory disease, is associated with the presence of endometrial foci. Pain, one of its typical symptoms, has been reported as a constant stressor, but the etiology and pathogenesis of EM-associated pain are unclear. In the present study, eutopic and ectopic endometrium samples from women with EM $(n=50)$ and normal endometrium samples from control subjects $(\mathrm{n}=20)$ were collected. Serum levels of prostaglandin $\mathrm{E}_{2}\left(\mathrm{PGE}_{2}\right)$, prostaglandin $\mathrm{F} 2 \alpha(\mathrm{PGF} 2 \alpha)$ and bradykinin (BK) were measured using commercial ELISA kits. The expression of the BKB1 receptor (BKB1R) protein was evaluated by immunohistochemical staining and western blot assay. The mRNA expression of BKB1R was measured by reverse transcription-quantitative PCR. The results revealed that there was a substantial increase in the protein and mRNA expression of BKB1R, as well as the release of $\mathrm{PGE}_{2}, \mathrm{PGF}_{2} \alpha$ and $\mathrm{BK}$ in the blood, in the EM group compared with that in the control group. Moreover, $\mathrm{PGE}_{2}, \mathrm{PGF} 2 \alpha$ and $\mathrm{BK}$ levels were significantly correlated with each other, as well as with the pain intensity of EM. The increased expression levels of BKB1R protein and mRNA were positively correlated with the pain degree of EM. Thus, these data indicated that BK and BKB1R were involved in the pathological onset of EM-associated pain and that they may play an important role in EM-related pain by inducing $\mathrm{PGE}_{2}$ and PGF2 $\alpha$. The data indicate a potential new therapeutic target for EM-related pain.
\end{abstract}

Correspondence to: Professor Jingwei Chen or Professor Shuancheng Zhang, Hebei Key Laboratory of Integrative Medicine on Liver-Kidney Patterns, Institute of Integrative Medicine, Hebei University of Chinese Medicine, 326 South Xinshi Road, Shijiazhuang, Hebei 050091, P.R. China

E-mail: chenjingwei1999@126.com

E-mail: shuancheng2002@163.com

*Contributed equally

Key words: endometriosis, bradykinin, bradykinin B1 receptor, prostaglandin $\mathrm{E}_{2}$, prostaglandin $\mathrm{F} 2 \alpha$, pain

\section{Introduction}

Endometriosis (EM) is characterized by the presence of endometrial foci outside the uterus; it is considered a significant health issue and is commonly observed in women of reproductive age, affecting $\sim 15 \%$ of women in Asia (1). EM is often accompanied by menstrual disorders, a pelvic mass, dysmenorrhea, chronic pelvic pain, infertility and a significant decline in quality of life (2). The standard methods of treatment include drug therapies that inhibit the ovarian activity or conservative surgical resection of EM. However, some of the challenges accompanying EM include the severe side effects resulting from the long-term use of painkillers and hormone therapies, and the high rate of recurrence, which is expected after the treatment is discontinued or even after undergoing a surgical procedure (3). Due to the chronic and recurrent features, the current treatment strategies of EM still focus on pain relief. As a primary and continuous symptom, EM-associated pain has a significant impact on the physical and mental health of patients, and is considered the primary reason for individuals to seek medical care. There has been a continuous debate regarding the development of strategies to optimize the management of EM-associated pain (4). The underlying mechanism related to the onset of EM-associated pain is unclear. Therefore, it is necessary to explore the pain pathways involved in EM to design more effective treatment strategies that will target the underlying causes of this disease. Although the pathogenesis of EM remains unclear, the role of prostaglandin $\mathrm{E}_{2}\left(\mathrm{PGE}_{2}\right)$ and prostaglandin $\mathrm{F} 2 \alpha(\mathrm{PGF} 2 \alpha)$ in various female reproductive processes, particularly in EM-associated infertility and pain, is well documented $(5,6)$, indicating the direct association between prostaglandins and the persistent pain of EM.

Furthermore, abnormal expression of $\mathrm{PGE}_{2}$ and $\mathrm{PG} 2 \alpha$ receptors has been observed in patients with EM (7). Although it is clear that $\mathrm{PGE}_{2}$ and PGF2 $\alpha$ play an essential role in EM, the precise mechanism is still unclear. Prostaglandins are lipid molecules obtained from arachidonic acid via enzymatic hydrolysis. $\mathrm{PGE}_{2}$ and $\mathrm{PGF} 2 \alpha$ are mainly produced by the reproductive system. Being a key mediator of inflammation, $\mathrm{PGE}_{2}$ contributes to the development of hypersensitivity to pain by overexciting sensory neurons. PGF $2 \alpha$ is a type of 
vasoconstrictor; therefore, an aberrant increase in its expression can cause the contraction of uterine smooth muscles and blood vessels, enhancing the algogenic effect of bradykinin (BK) and ultimately causing spastic pain (8). BK is known as one of the most algogenic substances (9); when the tissue is impaired by noxious stimuli, BK is released from the tissue and binds to one of the nociceptive receptors at the nerve terminal (10). As a nonapeptide, BK has attracted a lot of attention due to its potent pain-inducing effect within the human body $(11,12)$. Several studies have reported the interaction between prostaglandins and $\mathrm{BK}$ in the pathological process of pain induction; $\mathrm{BK}$ is also known to induce the synthesis of $\mathrm{PGE}_{2}$ in dermal fibroblasts (13). In our previous studies $(14,15)$, non-clinical and clinical experiments were performed to explore the pathogenesis of EM. Abnormally high levels of PGF $2 \alpha$ and BK were found in an EM model, indicating that PGF2 $\alpha$ and BK had a crucial role in the pathology of EM. Thus, an evaluation of whether BK/BKB1 receptor (BKB1R), $\mathrm{PGE}_{2}$ and PGF $2 \alpha$ promoted the onset of EM in a synergistic manner and an assessment of their mutual associations was required to understand the mechanism of EM-associated pain. Thus, in the present study, the role of $\mathrm{PGE}_{2}, \mathrm{PGF} 2 \alpha$, BK and $\mathrm{BKB} 1 \mathrm{R}$ in the development and maintenance of EM-associated pain was investigated.

\section{Materials and methods}

Study subjects. General conditions. Serum and eutopic and ectopic samples were collected during the proliferative phase of the menstrual cycle from 50 women with EM (EM group), aged $38.34 \pm 5.32$ years, whose diagnosis was confirmed based on pathological examinations after laparoscopic surgery at the Fourth Hospital of Shijiazhuang (Shijiazhuang, China) between January 2019 and December 2020. All participants provided written informed consent for participation. The degree of dysmenorrhea was assessed in the EM group based on the Visual Analog Scale (VAS) (16). A scale of 0 (without any pain) to 10 (most severe pain) was used for VAS scoring using a $10-\mathrm{cm}$ ruler; the patients placed a mark on the line according to their degree of dysmenorrhea before the operation and this was then measured by the physician. Based on the VAS scores of the 50 patients, 14 patients (aged 39.51 16.02 years) had a VAS score of 0 (non-pain group), while 36 patients (aged $36.93 \pm 7.28$ years) had different levels of VAS scores (pain group). EM was staged according to the American Society for Reproductive Medicine classification (17). Of the patients with EM, 11 had stage 1 disease, 14 had stage 2, 13 had stage 3 and 12 had stage 4. During the same time period in the Fourth Hospital of Shijiazhuang, control samples were also collected from 20 women (control group), aged $37.83 \pm 4.72$ years, who had undergone laparoscopic surgery due to benign gynecological disorders, such as uterine myoma without period pain. We exhibited no visible evidence of EM upon laparoscopy. All the patients in the control group provided written informed consent for participation. The study protocol was approved by the Ethics Committee of the Hebei University of Chinese Medicine (approval no. YXLL2015001).

Inclusion criteria. Patients were included in the study based on the following parameters: i) Premenopausal women aged
20-50 years; ii) no medical complications; iii) no hormonal medication for at least 1 month before sample collection; and iv) confirmed EM diagnosis via pathological examination.

Exclusion criteria. Patients were excluded from the study if they had any of the following: i) Pelvic infection or malignant pelvic tumor; ii) cardiovascular complications, liver/kidney/blood diseases or rectal cancer; iii) consumption of hormonal medication within the month before the operation; and iv) any neurological disorders.

Tissue collection. Before the operation, venous blood $(3 \mathrm{ml})$ was collected from the elbow via venous puncture in each patient, followed by centrifugation at $1,800 \mathrm{x}$ g at $4^{\circ} \mathrm{C}$ for $10 \mathrm{~min}$ to separate the serum and storage at $-80^{\circ} \mathrm{C}$ for ELISA. On the day of the operation, eutopic and ectopic endometrial tissues were collected from the patients in the EM group and normal endometrium samples were collected from the patients in the control group. Some of the samples were immediately frozen in liquid nitrogen and then transferred to a $-80^{\circ} \mathrm{C}$ cryogenic refrigerator for western blotting and reverse transcription-quantitative PCR (RT-qPCR) analysis. The remaining samples were fixed in $4 \%$ paraformaldehyde for 1 week at $4^{\circ} \mathrm{C}$, then embedded in paraffin for hematoxylin and eosin (H\&E) and immunohistochemical (IHC) staining.

Serum BK, $P G E_{2}, P G F 2 \alpha$ measurement. Serum levels of $\mathrm{BK}, \mathrm{PGE}_{2}$ and PGF $2 \alpha$ were measured using commercially available ELISA kits (BK ELISA kit: Enzo Life Science, Inc.; cat. no. ADI-900-206; PGF2 $\alpha$ ELISA kit: Enzo Life Science, Inc.; cat. number, ADI-900-069; and PGE 2 ELISA kit: Cayman Chemical Company; cat. no. 514010), following the manufacturer's instructions.

$H \& E$ staining. Paraffin tissues were sliced into 4- $\mu$ m sections, which were successively treated with xylene, anhydrous ethanol, $90 \%$ ethanol and $80 \%$ ethanol, then rinsed in distilled water for $5 \mathrm{~min}$, followed by hematoxylin staining for $5 \mathrm{~min}$ and eosin staining for 3-5 $\mathrm{min}$ at room temperature. Staining was observed under an electron microscope at $\mathrm{x} 400$ magnification.

$I H C$ staining for the detection of $B K B 1 R$. Serial tissue sections (4- $\mu \mathrm{m}$ thick) were washed with phosphate-buffered saline (PBS) and treated with 3\% hydrogen peroxide to block endogenous peroxidase activity at room temperature for $15 \mathrm{~min}$. The sections were incubated with primary antibody for BKB1R (Abcam; cat. no. ab75148; dilution, 1:200) overnight at $4^{\circ} \mathrm{C}$, and then with HRP-conjugated Affinipure goat anti-rabbit IgG (ProteinTech Group, Inc.; cat. no. SA00001-2; dilution, 1:2,000) at room temperature for $1 \mathrm{~h}$, followed by washing with PBS. Finally, the sections were counterstained with hematoxylin at room temperature for $5 \mathrm{~min}$, and mounted in resinene (cat. no. 10004160; Sinopharm Chemical Reagent Co., Ltd.).

The expression of BKB1R-positive cells was characterized via IHC by pale brown staining of the cytoplasm. A total of 10 high-power fields were randomly selected to count the BKB1R-positive cells in each sample under a light microscope, analyzed the data using the HMIAS-2000 pathology picture 
analysis system (Qianping Audiovisual Company) and evaluated it based on optical density.

Western blot analysis for measuring BKBIR. Radioimmunoprecipitation assay (RIPA) lysis buffer containing protease inhibitor (cat. no. BB3201; BestBio) was used to lyse the tissues, which where then homogenized in the lysis buffer. Following this, the lysis buffer was kept on ice for $30 \mathrm{~min}$, centrifuged at $8,000 \mathrm{xg}$ at $4^{\circ} \mathrm{C}$ for $15 \mathrm{~min}$ and diluted in 5X sample loading buffer (cat. no. G2013-100ML; Servicebio). Next, the supernatant was collected and the concentration of protein was determined using a Bradford assay. Protein samples were separated on $10 \%$ gels via SDS-PAGE with $5 \mu \mathrm{l}$ per lane, followed by transfer onto a polyvinylidene fluoride membrane. The non-specific sites on the membrane were blocked by incubation in 5\% skimmed milk for $2 \mathrm{~h}$ at room temperature, followed by overnight incubation at $4^{\circ} \mathrm{C}$ with the primary antibodies for BKB1R (Abcam; cat. no. ab75148; dilution, 1:200) and $\beta$-actin (Hangzhou HuaAn Biology Technology Ltd., Co.; cat. no. R130605; dilution, 1:2,000). Next, the membranes were washed and incubated with the secondary antibody (anti-rabbit IgG antibody; Protein Tech Group, Inc.; cat. no. SA00001-2; dilution, 1:5,000) for $1 \mathrm{~h}$ at room temperature. Protein bands were visualized using an electrochemiluminescence (ECL) kit (cat. no. P10300; New Cell \& Molecular Biotech Co., Ltd.), prior to being analyzed using Quantity One ${ }^{\circledR}$ 1-D Analysis Software v4.6 (Bio-Rad Laboratories, Inc.). Data are presented as a ratio of BKB1R//-actin.

$R T$-qPCR for measuring the mRNA expression of BKBIR. RNA from tissues was extracted using an E.Z.N.A. ${ }^{\circledR}$ Total RNA kit II (cat. no. R6934-01; Omega Bio-Tek, Inc.) according to the manufacturer's instructions. Total RNA was reverse transcribed to cDNA using an Mon Script ${ }^{\mathrm{TM}}$ RT III All-in-one mix with dsDNA (cat. no. MR05101; Monad Biotech Co., Ltd.) for incubation at $55^{\circ} \mathrm{C}$ for $10 \mathrm{~min}$ following the manufacturer's instructions. The primers were purchased from Shanghai Sangon Biotechnology Co., Ltd. The synthetic sequences of the primers were as follows: BKB1R, forward, 5'-AACAAC TAGTCACCTAAGGTCC-3' and reverse 5'-TCTCAAGGT TGCTGGCAGAG-3'; GAPDH, forward, 5'-TCCAAAATC AAGTGGGGCGA-3' and reverse, 5'-AAATGAGCCCCA GCCTTCTC-3'. qPCR was performed using Mon Amp ${ }^{\text {TM }}$ Chemo HS qPCR Mix (cat. no. MQ00401; Monad Biotech Co., Ltd.). The following thermocycling conditions were used for the qPCR: Initial denaturation at $95^{\circ} \mathrm{C}$ for $10 \mathrm{~min}$, followed by 40 cycles at $95^{\circ} \mathrm{C}$ for $15 \mathrm{sec}$ and $60^{\circ} \mathrm{C}$ for $60 \mathrm{sec}$. The quantitation cycle $(\mathrm{Cq})$ method was used, and the relative transcript number of the target gene was normalized to that of GAPDH using the $2^{-\Delta \Delta C q}$ method (18). The reactions were run in triplicate using the Applied Biosystems ${ }^{\mathrm{TM}} 7500$ Real-Time PCR system and results were analyzed with the associated SDS 2.0 software (Thermo Fisher Scientific, Inc.).

Statistical analysis. All statistical analyses were performed using SPSS software v22.0 (IBMCorp.). Statistical comparisons were performed using one-way analysis of variance (ANOVA) for $>2$ groups, followed by LSD post hoc test. Student's unpaired t-tests were performed to test the significance
Table I. Comparison of serum BK, $\mathrm{PGE}_{2}$ and PGF2 $\alpha$ levels between two groups (mean $\pm \mathrm{SD}$ ).

\begin{tabular}{lcccc}
\hline Group & $\mathrm{n}$ & $\mathrm{BK}, \mathrm{ng} / \mathrm{ml}$ & $\mathrm{PGE}_{2}, \mathrm{pg} / \mathrm{ml}$ & $\mathrm{PGF} 2 \alpha, \mathrm{ng} / \mathrm{ml}$ \\
\hline Control & 20 & $4.46 \pm 1.19$ & $548.94 \pm 165.22$ & $6.44 \pm 1.97$ \\
EM & 50 & $5.70 \pm 1.60^{\mathrm{b}}$ & $684.12 \pm 228.10^{\mathrm{a}}$ & $13.64 \pm 5.88^{\mathrm{b}}$ \\
\hline
\end{tabular}

${ }^{\mathrm{a}} \mathrm{P}<0.05$ and ${ }^{\mathrm{b}} \mathrm{P}<0.01$ vs. control group. $\mathrm{BK}$, bradykinin; $\mathrm{PGE}_{2}$, prostaglandin $\mathrm{E}_{2} ; \mathrm{PGF} 2 \alpha$, prostaglandin $\mathrm{F} 2 \alpha$; EM, endometriosis.

Table II. Comparison of serum BK, $\mathrm{PGE}_{2}$ and PGF2 $\alpha$ levels among three groups (mean $\pm \mathrm{SD}$ ).

\begin{tabular}{lcccc}
\hline Group & $\mathrm{n}$ & $\mathrm{BK}, \mathrm{ng} / \mathrm{ml}$ & $\mathrm{PGF} 2 \alpha, \mathrm{ng} / \mathrm{ml}$ & $\mathrm{PGE}_{2}, \mathrm{pg} / \mathrm{ml}$ \\
\hline Control & 20 & $4.46 \pm 1.19$ & $6.44 \pm 1.97$ & $548.94 \pm 165.22$ \\
Non-pain & 14 & $5.02 \pm 1.59^{\mathrm{b}}$ & $9.68 \pm 3.28^{\mathrm{b}}$ & $584.23 \pm 173.10^{\mathrm{b}}$ \\
Pain & 36 & $5.97 \pm 1.57^{\mathrm{a}}$ & $15.18 \pm 5.98^{\mathrm{a}}$ & $722.96 \pm 237.00^{\mathrm{a}}$ \\
\hline
\end{tabular}

${ }^{\mathrm{a}} \mathrm{P}<0.01$ vs. control group. ${ }^{\mathrm{b}} \mathrm{P}<0.05$ vs. pain group. $\mathrm{BK}$, bradykinin; $\mathrm{PGE}_{2}$, prostaglandin $\mathrm{E}_{2} ; \mathrm{PGF} 2 \alpha$, prostaglandin $\mathrm{F} 2 \alpha$; EM, endometriosis.

between two independent samples. The correlation between two normally distributed variables was evaluated via linear correlation analysis with Pearson's correlation coefficient, and the correlation between VAS score and other variables was assessed with Spearman's correlation analysis. All data are presented as the mean $\pm \mathrm{SD}$, and $\mathrm{P}<0.05$ was used to indicate a statistically significant difference.

\section{Results}

Serum concentrations of $B K, P G E_{2}$ and $P G F 2 \alpha$. There was a significant increase in the concentration of $\mathrm{BK}(\mathrm{P}<0.01), \mathrm{PGE}_{2}$ $(\mathrm{P}<0.05)$ and $\mathrm{PGF} 2 \alpha(\mathrm{P}<0.01)$ in the EM group compared with that in the control group (Table I).

Serum concentrations of $B K, P G E_{2}$ and $P G F 2 \alpha$ in the three groups. The concentration of BK in the pain group was significantly higher than that in the control $(\mathrm{P}<0.01)$ and non-pain $(\mathrm{P}<0.05)$ groups; however, there was no statistical significance between the control and non-pain group $(\mathrm{P}>0.05)$. The concentration of $\mathrm{PGE}_{2}$ in the pain group was significantly higher than that in the control $(\mathrm{P}<0.01)$ and non-pain $(\mathrm{P}<0.05)$ groups; however, there was no statistical significance between the control and non-pain groups $(\mathrm{P}>0.05)$. The concentration of PGF2 $\alpha$ in the pain group was also significantly higher than that in the control $(\mathrm{P}<0.01)$ and non-pain $(\mathrm{P}<0.05)$ groups, and there was no statistical significance between the control and non-pain groups $(\mathrm{P}>0.05)$ (Table II).

Correlation analysis in EM. To understand the associations between VAS and the serum molecules in EM, a correlation analysis was performed for $\mathrm{BK}, \mathrm{PGE}_{2}, \mathrm{PGF} 2 \alpha$ and VAS. VAS was positively correlated with $\mathrm{BK}, \mathrm{PGE}_{2}$ and $\mathrm{PGF} 2 \alpha(\mathrm{P} \leq 0.01)$, PGF $2 \alpha$ was positively correlated with $\mathrm{BK}$ and $\mathrm{PGE}_{2}(\mathrm{P} \leq 0.01$ 
Table III. Correlation analysis in endometriosis.

\begin{tabular}{lccccccc}
\hline Value & VAS vs. BK & VAS vs. PGE & VAS vs. PGF2 $\alpha$ & PGE $_{2}$ vs. BK & BK vs. PGF2 $\alpha$ & PGE $_{2}$ vs.PGF2 $\alpha$ & Stage vs. VAS \\
\hline r value & 0.401 & 0.611 & 0.457 & 0.303 & 0.458 & 0.354 & 0.518 \\
P-value & 0.004 & $\leq 0.001$ & $\leq 0.001$ & 0.033 & $\leq 0.001$ & 0.012 & $\leq 0.001$ \\
\hline
\end{tabular}

VAS, visual analog scale; BK, bradykinin; $\mathrm{PGE}_{2}$, prostaglandin $\mathrm{E}_{2} ; \mathrm{PGF} 2 \alpha$, prostaglandin $\mathrm{F} 2 \alpha$.

and $\mathrm{P}<0.05)$, and $\mathrm{PGE}_{2}$ was correlated with $\mathrm{BK}(\mathrm{P}<0.05)$. In order to explore the association between disease stage and the severity of pain symptoms, a correlation analysis was performed, which found that VAS score was correlated with stage $(\mathrm{P} \leq 0.01)$. Table III shows the results of the correlation analysis. Fig. 1 shows the scatter plots between the two variables.

$H \& E$ staining analysis. In the control group, endometrial tissue morphology was regular, cells were not damaged or missing, and no pericellular inflammatory factors were observed. The endometrial tissue morphology in the EM group was irregular in shape, with most cells incomplete, damaged or missing. Complete glands or stroma were observed in the ectopic foci and the simple columnar epithelium of the glands exhibited mild disorder (Fig. 2).

Expression of BKB1R by immunohistochemistry. Next, an IHC analysis of the endometrium in the different groups was performed to investigate the expression and localization of BKB1R protein. The BKB1R protein was mainly localized on the cytoplasm of endometrial stroma or glands with brown granular staining. The expression level of BKB1R in the eutopic endometrium of the pain group was significantly higher than that in the control and non-pain groups (both $\mathrm{P}<0.01$ ), and there was no significant difference between the control and non-pain groups $(\mathrm{P}>0.05)$. Additionally, a significantly higher expression level of BKB1R was observed in the ectopic endometrium in the pain group compared with the non-pain group $(\mathrm{P}<0.01)$ (Fig. 3). These results suggested excessively high secretion of BKB1R protein in the pain group.

Expression of BKB1R as assessed by western blotting. The results of western blotting analysis showed a significantly higher expression level of BKB1R protein in the eutopic endometrium in the pain group compared with the control and non-pain groups (all $\mathrm{P}<0.01$ ), and there was no significant difference between the control and non-pain groups $(\mathrm{P}>0.05)$. Additionally, a significantly higher expression level of BKB1R protein was observed in the ectopic endometrium of the pain group compared with that in the non-pain group $(\mathrm{P}<0.01)$ (Fig. 4).

Expression of BKBIR $m R N A$ as assessed by RT-qPCR . RT-qPCR was performed to investigate the mRNA expression of BKB1R in EM. The expression level of BKB1R mRNA in the eutopic endometrium from the pain group was significantly higher compared with that in the control and non-pain groups (all $\mathrm{P}<0.01$ ), and there was no difference between control and non-pain groups $(\mathrm{P}>0.05)$. Furthermore, the expression
Table IV. Comparison of BKB1 receptor mRNA expression assessed by reverse transcription-quantitative PCR (mean $\pm \mathrm{SD})$.

Group $\quad n$ Eutopic endometrium Ectopic endometrium

\begin{tabular}{lllc}
\hline Control & 20 & $0.90 \pm 0.05$ & - \\
Non-pain & 14 & $1.39 \pm 0.12^{\mathrm{b}}$ & $1.76 \pm 0.33^{\mathrm{b}}$ \\
Pain & 36 & $3.50 \pm 1.12^{\mathrm{a}}$ & $3.78 \pm 0.86$ \\
\hline
\end{tabular}

${ }^{a} \mathrm{P}<0.01$ vs. control group; ${ }^{b} \mathrm{P}<0.01$ vs. pain group.

level of BKB1R mRNA in the ectopic endometrium from the pain group was significantly higher than that in the non-pain group $(\mathrm{P}<0.01)$. These results showed that BKB1R mRNA was significantly upregulated in the lesions in EM, especially in the pain group (Table IV).

\section{Discussion}

EM is a complex inflammatory disease of the pelvis, characterized by dysmenorrhea, dyspareunia and chronic pelvic pain. Pain is one of the typical symptoms that severely affect the quality of life of a patient. The pathophysiology of EM involves biological mechanisms that induce pain. Although there are numerous studies (19-21) on the related biological processes, the pathological processes related to the onset of EM-associated pain have remained unclear. Prostaglandins, such as $\mathrm{PGE}_{2}$ and PGF2 $\alpha$, are mainly derived from the reproductive system (7). Relevant studies have revealed that $\mathrm{PGE}_{2}$ and PGF2 $\alpha$ are involved in various diseases, particularly $\mathrm{EM}$, by regulating the cyclic changes in the endometrium. $\mathrm{PGE}_{2}$ and PGF2 $\alpha$ are known to be abnormally expressed in the peritoneal fluid of patients with EM, which might be associated with the pathogenesis of EM (22). Furthermore, prostaglandins are also considered to play multiple roles in the etiology of EM-associated infertility and pain $(6,23-25)$. To date, several studies have confirmed that there is a specific association between prostaglandins and EM-associated pain $(26,27)$.

We previously showed that the serum levels of PGF $2 \alpha$ were abnormally elevated in an EM-associated dysmenorrhea model of mice (15), indicating that PGF2 $\alpha$ might be involved in the pathogenesis of EM-associated pain. High concentrations of PGF $2 \alpha$ can cause uterine smooth muscle contraction, and the consequent reduction of blood flow may cause uterine ischemia and anoxia, which may lead to the accumulation of acidic metabolites, causing dysmenorrhea (28). Also, 

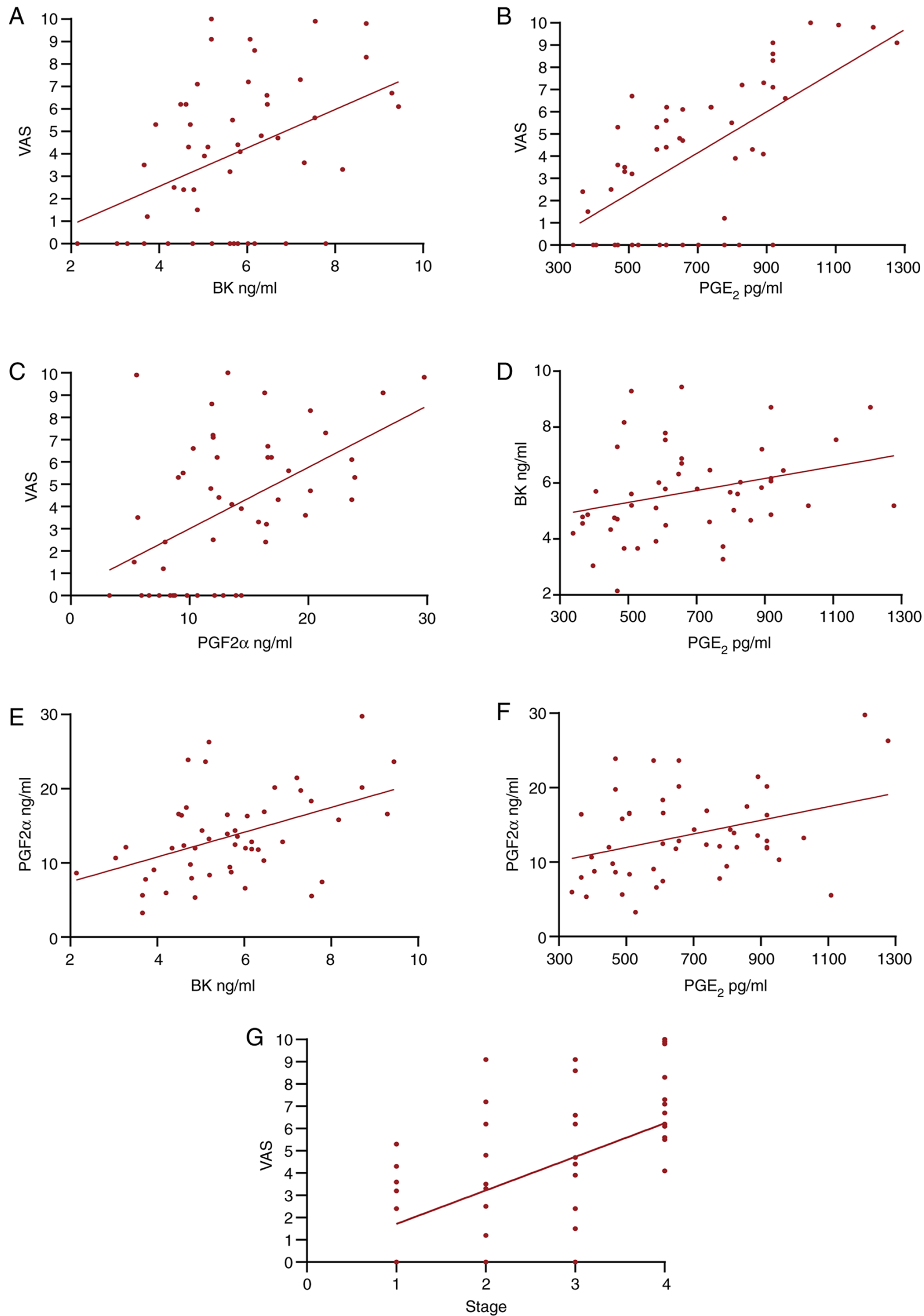

Figure 1. Correlation analysis. (A) Correlation between VAS score and BK. (B) Correlation between VAS score and PGE 2 . (C) Correlation between VAS score and PGF2 $\alpha$. (D) Correlation between BK and PGF2 $\alpha$. (E) Correlation between PGE 2 and BK. (F) Correlation between PGE 2 and PGF2 $\alpha$. (G) Correlation between stage and VAS score. VAS, visual analog scale; BK, bradykinin; $\mathrm{PGE}_{2}$, prostaglandin $\mathrm{E}_{2}$; PGF2 $\alpha$, prostaglandin $\mathrm{F} 2 \alpha$. 

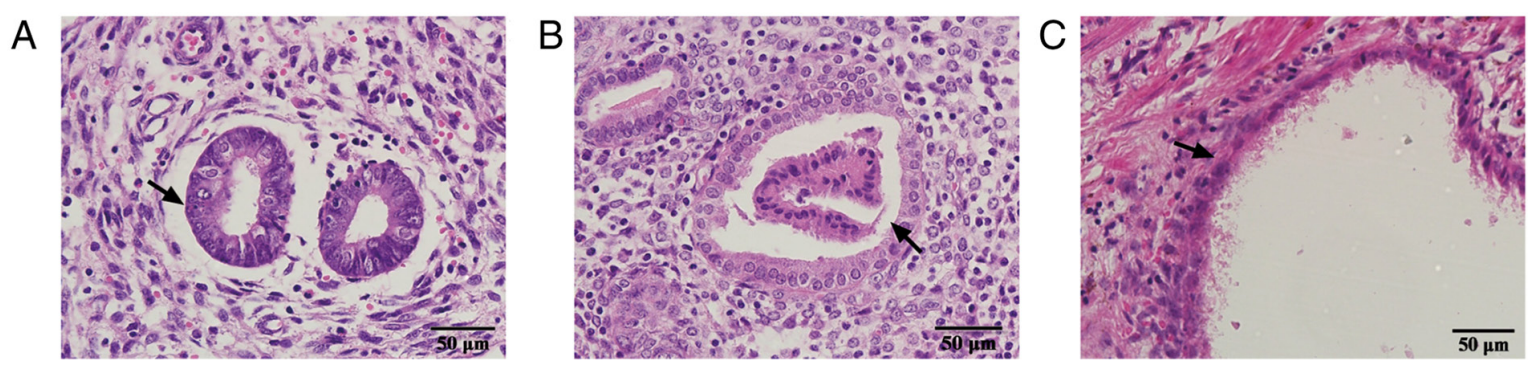

Figure 2. Hematoxylin and eosin staining. (A) Normal endometrium of the control group; (B) eutopic endometrium of the EM group; and (C) ectopic endometrium of the EM group. Magnification, x400. EM, endometriosis.
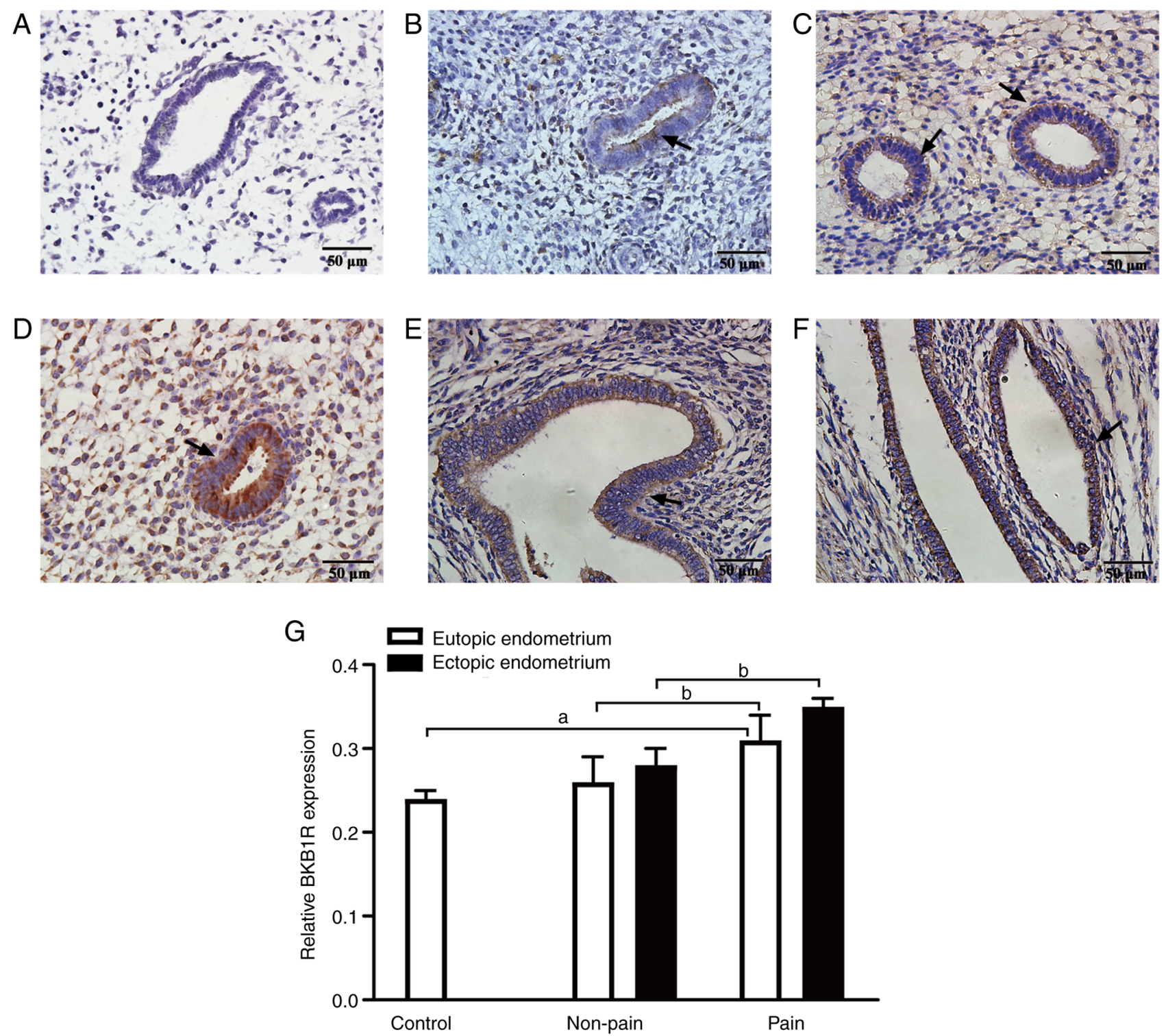

Figure 3. Expression of BKB1R in the eutopic and ectopic endometrium as assessed via immunohistochemistry. (A) Control IgG; (B) normal endometrium of the control group; (C) eutopic endometrium of the non-pain group; (D) eutopic endometrium of the pain group; (E) ectopic endometrium of the non-pain group; (F) ectopic endometrium of the pain group. (G) Comparison of BKB1R in eutopic and ectopic endometrium by IHC. Magnification, $\mathrm{x} 400$. ${ }^{\mathrm{a}} \mathrm{P}<0.01$; ${ }^{\mathrm{b}} \mathrm{P}<0.01$. BKB1R, BKB1 receptor.

abnormally high levels of prostaglandins can cause pain by inducing aseptic inflammation, increasing vascular permeability and enhancing the pain effect of pain molecules such as BK (29). BK is considered a mediator of inflammatory pain; its elevated levels after tissue injury and inflammation occur via the activation of two types of GPCRs, termed BKB1R and BKB2R (30). The B2 receptor is constitutively expressed in several tissues, while the B1 receptor is minimally 

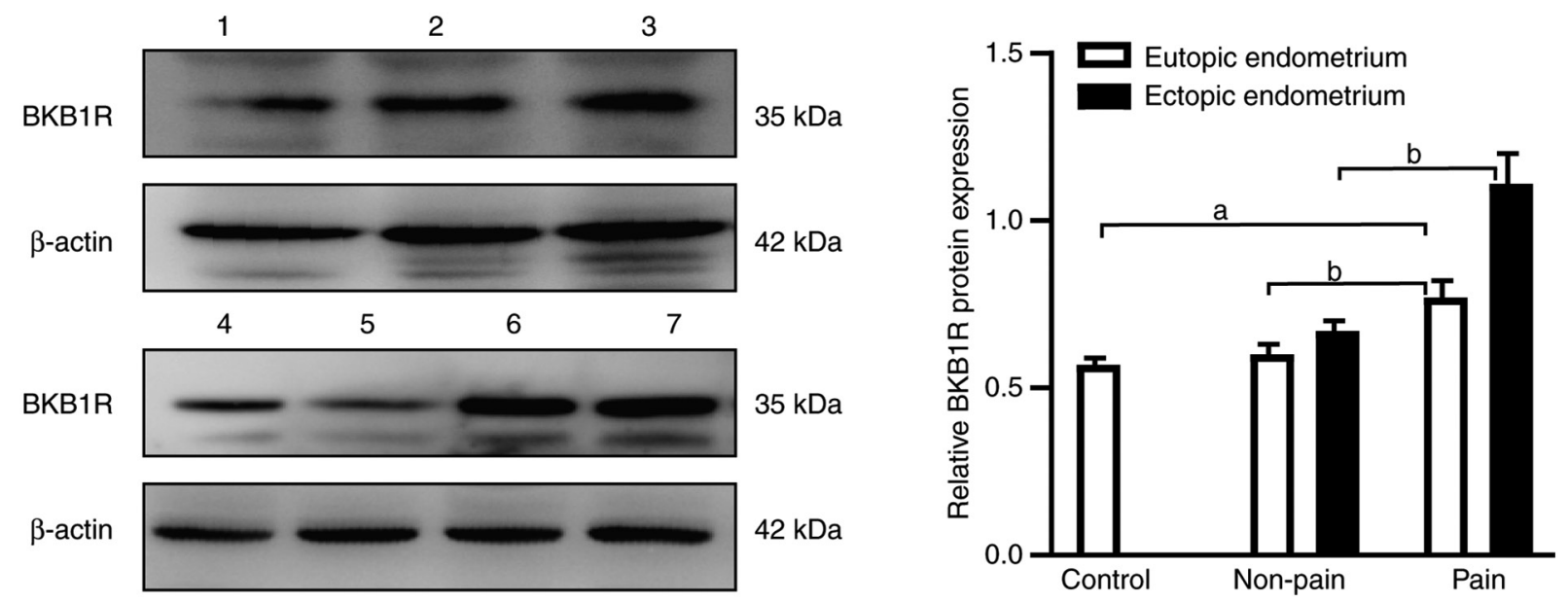

Figure 4. BKB1R protein expression as assessed by western blotting. Lane 1, normal endometrium of the control group; lane 2, eutopic endometrium of the non-pain group; lane 3, eutopic endometrium of the pain group; lanes 4 and 5, ectopic endometrium of the non-pain group; lanes 6 and 7 , ectopic endometrium of the pain group. ${ }^{a} \mathrm{P}<0.01 ;{ }^{b} \mathrm{P}<0.01$. BKB1R, BKB1 receptor.

expressed in physiological conditions, but its expression might be induced under different pathological conditions, such as inflammation. BKB1R is an inducible GPCR; it is induced or upregulated at the site of injury or inflammation. In particular, BKB1R has been shown to be involved in the pathogenesis of numerous inflammatory diseases (31). Recent reports (32-34) have suggested a potential role of the B1 receptor in various pathophysiological processes. For example, it may be implicated in inflammation, hyperalgesia, hyperthermia and experimental diabetes. In these conditions, the $\mathrm{B} 1$ receptor has been found to be significantly upregulated; it plays a critical role in chronic pain, and it is one of the major causes of prolonged pain (35), playing an important role in the regulation of hyperalgesia and pain. The combination of $\mathrm{BK}$ and $\mathrm{B} 1$ receptor results in the activation of phospholipase $\mathrm{A}_{2}$ and stimulates arachidonic acid to release prostaglandins, causing pain (36). The present study showed that serum levels of $\mathrm{BK}, \mathrm{PGE}_{2}$ and $\mathrm{PGF} 2 \alpha$ were upregulated in patients with EM compared with those in the control group, indicating that $\mathrm{BK}, \mathrm{PGE}_{2}$ and $\mathrm{PGF} 2 \alpha$ were involved in the development of EM. Inflammation is one of the causative factors of pain in EM and previous studies have shown that prostaglandins and BK are involved in inflammation and pain (37-39). In the present study, a correlation analysis was performed to determine whether these molecules were correlated with the clinical characteristics of EM and a positive correlation was found between the VAS score and $\mathrm{BK}, \mathrm{PGE}_{2}$ and PGF $2 \alpha$ expression. Further correlation analysis indicated that $\mathrm{PGE}_{2}$, PGF $2 \alpha$ and BK levels were significantly correlated with each other, as well as with the pain intensity of EM. These results suggested that $\mathrm{BK}, \mathrm{PGE}_{2}$ and $\mathrm{PGF} 2 \alpha$ played crucial roles in the onset of EM-associated pain. Additionally, the results of the present study showed that the expression levels of BKB1R protein and mRNA in the patients with EM were significantly upregulated compared with those of the control group. These results were consistent with those of a previous study (40). The present study investigated apparent changes in the protein and gene expression levels of BKB1R, and the serum levels of $\mathrm{BK}, \mathrm{PGE}_{2}$ and $\mathrm{PGF} 2 \alpha$, as well as their association with pain symptoms. Based on the results, we hypothesized that, along with the cyclical changes in the ectopic endometrium in EM, surrounding tissues were injured and released various types of pain mediators, such as BK, which is a potent algogenic substance and directly participates in the occurrence of EM-associated pain. Also, after binding to the BKB1R, it induced the upregulation of prostaglandins, such as $\mathrm{PGE}_{2}$ and PGF2 $\alpha$, causing pain. Therefore, based on present study results, it was speculated that $\mathrm{BK}, \mathrm{BKB} 1 \mathrm{R}, \mathrm{PGE}_{2}$ and PGF2 $\alpha$ were involved in the development of EM and served a synergistic effect in the pathology of EM-associated pain.

In our previous study (15), a mouse EM model was used to demonstrate that the control of BK by herbal medicine could inhibit the development of EM and relieve dysmenorrhea, suggesting that it could significantly help treat EM-associated pain by downregulating BK and BKB1R. Furthermore, certain previous studies demonstrated that BK regulated autophagic and apoptotic responses (41-43). Recent studies have shown that BKB1R is a positive regulator of autophagy, and its overexpression may be involved in the autophagy of microglia, which causes neuropathic pain (44). BK/BKB1R is known to be involved in the development of pain in various ways. Therefore, one potential way to treat pain might include blocking BK. In the present study, with regard to the disease stage, the severity of pain symptoms was correlated significantly with the stage of the disease, and this finding is in agreement with the results of a previous study (45). The present study results provided a potential molecular mechanism by which $\mathrm{PGE}_{2}, \mathrm{PGF} 2 \alpha$ and $\mathrm{BK} / \mathrm{BKB} 1 \mathrm{R}$ are involved in EM-associated pain, suggesting a possible target for the treatment of EM-associated pain. A correlation was found between the VAS score of menstrual pain and the concentration of molecules, as well as the stage of the disease, so the results may be helpful in the development of biomarkers to determine the severity of EM-associated pain.

The present study does have limitations to be considered. First of all, samples were collected from only 50 patients with EM, and it would be necessary for the sample to be enlarged in order to confirm the conclusions. Secondly, the present study is a primary analysis of the mechanism of EM-associated 
pain focusing on $\mathrm{PGE}_{2}, \mathrm{PGF} 2 \alpha, \mathrm{BK}$ and BKB1R in EM tissues. Further studies are required to investigate the expression and cellular and subcellular location of BKB1R in primary cells and cell lines to further confirm any conclusions, as well as to further explore the molecular regulatory mechanism of pain-producing substances.

In conclusion, the present study shows that the onset of EM-associated pain is related to the release of several inflammatory mediators, including BK, BKB1R, $\mathrm{PGE}_{2}$ and PGF2 $\alpha$. However, the regulatory effects of these molecules on the onset of EM-associated pain in humans are still unclear. Thus, further studies are required to elucidate the possible role and specific mechanisms of these molecules in the pathogenesis of EM and to improve the quality of life of patients with EM. Since the overexpression of the BKB1R can result in elevated levels of pain after a longer stimulation interval, it is anticipated that BKB1R antagonists could act as potential therapeutic agents for the treatment of pain in EM. In the future, further meaningful studies should be conducted in order to improve therapy options and patient management.

\section{Acknowledgements}

Not applicable.

\section{Funding}

This study was supported by the National Natural Science Fund of China (grant nos. 82074483 and 81503608) and the S\&T Program of Hebei (grant nos. 21377725D and 213777116D).

\section{Availability of data and materials}

The datasets used and/or analyzed during the current study are available from the corresponding author on reasonable request.

\section{Authors' contributions}

$\mathrm{XM}$ and YL performed the experiments. $\mathrm{XF}$ and $\mathrm{MA}$ collected and analyzed the data. JC and SZ designed the study, drafted and reviewed the manuscript, and supervised the entire study. QL collected data and interpreted the results, and JY analyzed the data and drew the figures. JC and SZ confirm the authenticity of all the raw data. All the authors have read and approved the final manuscript.

\section{Ethics approval and consent to participate}

Study protocols involving human subjects were approved by the Ethics Committee of the Hebei University of Chinese Medicine (Shijiazhuang, China; approval no. YXLL2015001), and written informed consent was obtained from all subjects.

\section{Patient consent for publication}

Not applicable.

\section{Competing interests}

The authors declare that they have no competing interests.

\section{References}

1. Yamamoto A, Johnstone EB, Bloom MS, Huddleston HG and Fujimoto VY: A higher prevalence of endometriosis among Asian women does not contribute to poorer IVF outcomes. J Assist Reprod Genet 34: 765-774, 2017.

2. Alimi Y, Iwanaga J, Loukas M and Tubbs RS: The clinical anatomy of endometriosis: A review. Cureus 10: e3361, 2018.

3. Kim JH and Han E: Endometriosis and female pelvic pain. Semin Reprod Med 36: 143-151, 2018.

4. Nezhat C, Vang N, Tanaka PP and Nezhat C: Optimal management of endometriosis and pain. Obstet Gynecol 134: 834-839, 2019.

5. Ahmad SF, Akoum A and Horne AW: Selective modulation of the prostaglandin $\mathrm{F} 2 \alpha$ pathway markedly impacts on endometriosis progression in a xenograft mouse model. Mol Hum Reprod 21: 905-916, 2015.

6. Sacco K, Portelli M, Pollacco J, Schembri-Wismayer P and Calleja-Agius J: The role of prostaglandin $\mathrm{E}_{2}$ in endometriosis. Gynecol Endocrinol 28: 134-138, 2012.

7. Rakhila H, Bourcier N, Akoum A and Pouliot M: Abnormal expression of prostaglandins $\mathrm{E}_{2}$ and $\mathrm{F} 2 \alpha$ receptors and transporters in patients with endometriosis. Biomed Res Int 2015: 808146, 2015.

8. Bulun SE, Imir G, Utsunomiya H, Thung S, Gurates B, Tamura M and Lin Z: Aromatase in endometriosis and uterine leiomyomata. J Steroid Biochem Mol Biol 95: 57-62, 2005.

9. Linhart $\mathrm{O}$, Obreja $\mathrm{O}$ and Kress M: The inflammatory mediators serotonin, prostaglandin E2 and bradykinin evoke calcium influx in rat sensory neurons. Neuroscience 118: 69-74, 2003.

10. Mizumura K, Sugiura T, Katanosaka K, Banik RK and Kozaki Y: Excitation and sensitization of nociceptors by bradykinin: What do we know? Exp Brain Res 196: 53-65, 2009.

11. Petho G and Reeh PW: Sensory and signaling mechanisms of bradykinin, eicosanoids, platelet-activating factor, and nitric oxide in peripheral nociceptors. Physiol Rev 92: 1699-1775, 2012.

12. Meotti FC, Campos R, da Silva K, Paszcuk AF, Costa R and Calixto JB: Inflammatory muscle pain is dependent on the activation of kinin $B_{1}$ and $B_{2}$ receptors and intracellular kinase pathways. Br J Pharmacol 166: 1127-1139, 2012.

13. Nakano R, Kitanaka T, Namba S, Kitanaka N and Sugiya H: Protein kinase $\mathrm{C} \varepsilon$ regulates nuclear translocation of extracellular signal-regulated kinase, which contributes to bradykinin-induced cyclooxygenase-2 expression. Sci Rep 8: 8535, 2018.

14. Zhang Z, Yuan Y, He L, Yao X and Chen J: Involvement of angiotensin II receptor type $1 / \mathrm{NF}-\kappa \mathrm{B}$ signaling in the development of endometriosis. Exp Ther Med 20: 3269-3277, 2020.

15. Jingwei C, Huilan D, Ruixiao T, Hua Y and Huirong M: Effect of Bushenwenyanghuayu decoction on nerve growth factor and bradykinin/bradykinin B1 receptor in a endometriosis dysmenorrhea mouse model. J Tradit Chin Med 35: 184-191, 2015.

16. Osuga Y, Seki Y, Tanimoto M, Kusumoto T, Kudou K and Terakawa N: Relugolix, an oral gonadotropin-releasing hormone receptor antagonist, reduces endometriosis-associated pain in a dose-response manner: A randomized, double-blind, placebo-controlled study. Fertil Steril 115: 397-405, 2021.

17. Lee SY, Koo YJ and Lee DH: Classification of endometriosis. Yeungnam Univ J Med 38: 10-18, 2021.

18. Pfaffl MW: A new mathematical model for relative quantification in real-time RT-PCR. Nucleic Acids Res 29: e45, 2001.

19. Liu X, Zhang P, Li Y, Zhao N and Han H: The AMPK-mTOR axis requires increased MALAT1 expression for promoting granulosa cell proliferation in endometriosis. Exp Ther Med 21: $21,2021$.

20. Huang J, Chen X and Lv Y: HMGB1 mediated inflammation and autophagy contribute to endometriosis. Front Endocrinol (Lausanne) 12: 616696, 2021.

21. Machairiotis N, Vasilakaki S and Thomakos N: Inflammatory mediators and pain in endometriosis: A systematic review. Biomedicines 9: 54, 2021.

22. Ulug U, Goldman S, Ben-Shlomo I and Shalev E: Matrix metalloproteinase (MMP)-2 and MMP-9 and their inhibitor, TIMP-1, in human term decidua and fetal membranes: The effect of prostaglandin F(2alpha) and indomethacin. Mol Hum Reprod 7: 1187-1193, 2001.

23. Banu SK, Lee J, Speights VO Jr, Starzinski-Powitz A and Arosh JA: Cyclooxygenase-2 regulates survival, migration, and invasion of human endometriotic cells through multiple mechanisms. Endocrinology 149: 1180-1189, 2008. 
24. Ylikorkala O, Koskimies A, Laatkainen T, Tenhunen A and Viinikka L: Peritoneal fluid prostaglandins in endometriosis, tubal disorders, and unexplained infertility. Obstet Gynecol 63: 616-620, 1984

25. Schenken RS, Asch RH, Williams RF and Hodgen GD: Etiology of infertility in monkeys with endometriosis: Measurement of peritoneal fluid prostaglandins. Am J Obstet Gynecol 150: 349-353, 1984

26. McAllister SL, Giourgas BK, Faircloth EK, Leishman E, Bradshaw HB and Gross ER: Prostaglandin levels, vaginal innervation, and Cyst innervation as peripheral contributors to endometriosis-associated vaginal hyperalgesia in rodents. Mol Cell Endocrinol 437: 120-129, 2016.

27. Bulun SE: Endometriosis. N Engl J Med 360: 268-279, 2009.

28. French L: Dysmenorrhea. Am Fam Physician 71: 285-291, 2005.

29. Liclican EL, Nguyen V, Sullivan AB and Gronert K Selective activation of the prostaglandin E2 circuit in chronic injury-induced pathologic angiogenesis. Invest Ophthalmol Vis Sci 51: 6311-6320, 2010.

30. Hamza M, Wang XM, Adam A, Brahim JS, Rowan JS, Carmona GN and Dionne RA: Kinin B1 receptors contributes to acute pain following minor surgery in humans. Mol Pain 6 : $12,2010$.

31. Qadri F and Bader M: Kinin B1 receptors as a therapeutic target for inflammation. Expert Opin Ther Targets 22: 31-44, 2018.

32. Lau J, Rousseau J, Kwon D, Bénard F and Lin KS: A systematic review of molecular imaging agents targeting bradykinin $\mathrm{B} 1$ and B2 receptors. Pharmaceuticals (Basel) 13: 199, 2020.

33. Tang M, He F, Ma L, Liu P, Wang J and Zhu X: Bradykinin receptors in ischemic injury. Curr Neurovasc Res 15: 359-366, 2018.

34. Bertolini F, Carriero V, Bullone M, Sprio AE, Defilippi I, Sorbello V, Gani F, Di Stefano A and Ricciardolo FLM: Correlation of matrix-related airway remodeling and bradykinin B1 receptor expression with fixed airflow obstruction in severe asthma. Allergy 76: 1886-1890, 2021.

35. Moreau ME, Garbacki N, Molinaro G, Brown NJ, Marceau F and Adam A: The kallikrein-kinin system: Current and future pharmacological targets. J Pharmacol Sci 99: 6-38, 2005.
36. Okuse K: Pain signalling pathways: From cytokines to ion channels. Int J Biochem Cell Biol 39: 490-496, 2007.

37. Muscella A, Cossa LG, Vetrugno C and Marsigliante S: Bradykinin stimulates prostaglandin $\mathrm{E}_{2}$ release in human skeletal muscular fibroblasts. Mol Cell Endocrinol 507: 110771, 2020.

38. Bouhadfane M, Kaszás A, Rózsa B, Harris-Warrick RM, Vinay L and Brocard F: Sensitization of neonatal rat lumbar motoneuron by the inflammatory pain mediator bradykinin. Elife 4: e06195, 2015.

39. Baek SB, Shin MS, Han JH, Moon SW, Chang B, Jeon JW, Yi JW and Chung JY: Rocuronium bromide inhibits inflammation and pain by suppressing nitric oxide production and enhancing prostaglandin $\mathrm{E}_{2}$ synthesis in endothelial cells. Int Neurourol J 20: 296-303, 2016.

40. Yoshino O, Yamada-Nomoto K, Kobayashi M, Andoh T, Hongo M, Ono Y, Hasegawa-Idemitsu A, Sakai A, Osuga Y and Saito S: Bradykinin system is involved in endometriosis-related pain through endothelin-1 production. Eur J Pain 22: 501-510, 2018.

41. Hammerschmidt S, Kuhn H, Gessner C, Seyfarth HJ and Wirtz H: Stretch-induced alveolar type II cell apoptosis: Role of endogenous bradykinin and PI3K-Akt signaling. Am J Res Cell Mol Biol 37: 699-705, 2007.

42. Kaminskyy VO and Zhivotovsky B: Free radicals in cross talk between autophagy and apoptosis. Antioxid Redox Signal 21: 86-102, 2014

43. Xu X, Tu L, Jiang W, Feng W, Zhao CX and Wang DW: Bradykinin prevents the apoptosis of NIT-1 cells induced by TNF- $\alpha$ via the PI3K/Akt and MAPK signaling pathways. Int J Mol Med 29: 891-898, 2012

44. Xie H, Lu F, Liu W, Wang E, Wang L and Zhong M: Remimazolam alleviates neuropathic pain via regulating bradykinin receptor B1 and autophagy. J Pharm Pharmacol: Jun 1, 2021 (Epub ahead of print).

45. Al-Jefout M, Alnawaiseh N, Yaghi S and Alqaisi A: Prevalence of endometriosis and its symptoms among young jordanian women with chronic pelvic pain refractory to conventional therapy. J Obstet Gynaecol Can 40: 165-170, 2018.

(i) $(-)$ This work is licensed under a Creative Commons Attribution-NonCommercial-NoDerivatives 4.0 International (CC BY-NC-ND 4.0) License. 